\title{
Resultados das Semifinais das Olimpíadas de Química 2012
}

Nas disputadas provas que decorreram em Aveiro, Porto e Lisboa, no passado dia 3 de março, foram apurados os finalistas que competiram na fase final das Olimpíadas de Química+ 2012, na qual foi selecionado o grupo restrito de vencedores que representarão Portugal nas provas internacionais do próximo ano.

Uma vez mais, a acolher de forma entusiástica os participantes estiveram as equipas coordenadas pela Prof. Diana Pinto (Semifinal de Aveiro), Prof. Jorge Gonçalves (Semifinal do Porto) e Prof. Jorge Morgado (Semifinal de Lisboa).

Segue-se a descrição de cada uma das semifinais.

\section{Semifinal de Aveiro (Departamento de QuímICA, Universidade de Aveiro)}

Em Aveiro, as provas decorreram com grande sucesso, e nem a chuva que se fez sentir nesse dia causou problemas! A organização preparou uma atividade para os professores acompanhantes (Recursos pedagógicos para uma sociedade de consumo esclarecida - Projeto Dolceta, Grupo de Disseminação Dolceta Portugal, a cargo de José M.G. Pereira, Maria Clara Magalhães e Solange Burri), bem como um espetáculo final para todos, designado "Química em Espetáculo!!!". Quanto aos resultados das provas, estes revelaram-se bastante positivos e muito renhidos, sendo necessário avaliar o desempenho das equipas ao detalhe para determinar a sua seriação.

\section{Lista dos Vencedores da Semifinal DE AVEIRO}

Medalhas de Ouro

Escola Secundária Infanta D. Maria Coimbra

Prof. Responsáveis: Celeste Queija e Laura Nunes

Joana Inês Oliveira

João Luís Sousa Janela

Maria Carolina Amoedo Gonçalves
Medalhas de Prata

ES com 3. ${ }^{\circ}$ Ciclo do Ensino Básico Soares Basto - Oliveira de Azeméis

Prof. Responsáveis: Paula Cristina Ornelas e Ana Maria Santos

João Paulo Martins Rosa

Mariana Mendes Martins Coelho

Micael Marques Mendes

\section{Medalhas de Bronze}

ES com 3. ${ }^{\circ}$ Ciclo do Ensino Básico Dr. Mário Sacramento - Aveiro

Prof. Responsáveis: Cecília Veiga e José Manuel Nunes

Bruno Miguel Miguez Barroso

Juliana Couras Fernandes Silva

Manuel Tomás Farinha Caroço

\section{Diana Pinto}

Coordenadora da Semifinal de Aveiro

\section{Semifinal do Porto (Departamento} DE Química, FaCULDADE dE CIÊNCIAS, UNIVERSIDADE DO PORTO)

No passado dia 3 março teve lugar mais uma edição da semifinal Norte das Olimpíadas de Química+, no Departamento de Química e Bioquímica da Faculdade de Ciências da Universidade do Porto. Apresentaram-se a este evento 42 das 50 escolas inicialmente inscritas na plataforma web da SPQ. Para além da realização da prova, os estudantes e os professores acompanhantes tiveram a oportunidade de participar em várias atividades especialmente programadas para este dia. Esta edição contou com o apoio da Universidade do Porto, da Porto Editora e da Texto Editora, que gentilmente contribuíram com ofertas para os estudantes participantes, e da Casa das Ciências, que promoveu uma palestra de divulgação para os professores acompanhantes. Apurados os resultados, foram divulgadas as três equipas melhor classificadas.

Lista dos Vencedores da Semifinal DO PORTO

Medalhas de Ouro

Externato Cedros
Prof. Responsável: Nuno Francisco

Álvaro Samagaio

Emanuel Matias

João Francisco Souto

Medalhas de Prata

ES/3B Emídio Garcia - Bragança

Prof. Responsável: Luísa Fernandes

Ana Margarida Gomes

Filipe Mota

Joana Piloto

Medalhas de Bronze

Colégio Luso-Francês

Prof. Responsável: Sónia Marília Castro

João Daniel Moreira

Luís Daniel Alves

Maria Francisca Cunha

Jorge Gonçalves

Coordenador da Semifinal do Porto

\section{Semifinal de Lisboa (Instituto SUPERIOR TÉCNICO, UNIVERSIDADE TÉCNICA DE LISBOA)}

As atividades iniciaram-se com a receção aos participantes, alunos e professores, pelas $10 \mathrm{~h} 30 \mathrm{~min}$ na Torre de Química. Compareceram 37 escolas das 46 inicialmente previstas. As provas decorreram entre as $11 \mathrm{~h}$ e o meio-dia. Enquanto os alunos estavam concentrados na resolução dos problemas e desafios da prova, os professores puderam apreciar a exposição da Profa Clementina Teixeira, "Artesãos do Século XXI" (também acessível em http://web.ist.utl. $\mathrm{pt} /$ clementina/artesaos/), e trocar com ela impressões sobre esse trabalho. Seguiu-se o almoço na cantina dos serviços sociais, oferecido pela Reitoria da Universidade Técnica de Lisboa.

A tarde iniciou-se com as sessões de divulgação "Luz sobre as moléculas", apresentada pelo Prof. Mário Nuno Santos, Presidente da SPQ; e "Show de azoto", pela Profa Clementina Teixeira. Durante este período, vários professores do Departamento de Eng. Química 